\title{
Evaluation in EFL written stories
}

\section{Janusz Badio}

\section{University of Łódź, Poland}

\begin{abstract}
The structure of oral narratives, as studied by Labov \& Waletzky (1967) involves an abstract, orientation, complicating action, resolution, evaluation and coda. Narratives are presented on TV and radio news, newspapers as well as in everyday conversations (ErvinTripp \& Küntay, 1997), also during children's dramatic play (Ervin-Tripp \& Küntay, 1997), jokes (Badio, 2020), stories as rehearsal for action (Kiełkiewicz-Janowiak, 2015), stories as background of the meaning of lexical items, e.g. dirty money (Filar, 2015), advertisements and in a great number of other contexts. The different components of narratives as listed by Labov \& Waletzky (1967) include the complex category of evaluation. Characterisation and discussion of this unit of narrative constitutes the goal of the present article.
\end{abstract}

Key words: story, event, narrative structure, evaluation

\section{Introduction}

Labov and Waletzky (1967, pp. 28-35) argue that a narrative that only contains events of the complicating action ${ }^{1}$ seem hard to understand. The following transcription of a part of an oral narrative illustrates the point.

a) See he - they threw him out, you know

b) So he wanted to get back in, 'cause, you know, it was sn-raining

c) So he got on his boat

${ }^{1}$ One of the components of a narrative as studied by L\&W (1967) that contains the main events of a story or narrative. Their narrative schema contains: abstract, orientation, complicating action, evaluation, resolution and coda. The abstract at the beginning of a story is a general statement about what happened. Orientation introduces the reader or listener to the context: location, setting, time and characters. It is usually placed at the beginning of a story but orienting comments can be found anywhere in a narrative. The same is true of the part called evaluation, which presents the story-teller's opinions and emotions regarding the events that took place. Resolution presents the outcome of the events that lead to the most reportable event for which a story is worth telling, whereas the coda is a statement, not always present, that is used to return to the here and now, such as, Well, yes, that's how it happened [invented example J.B.]. 

d) and tried to - go somewhere else
e) and the boat went over
f) and he tried to swim
g) and this other man was swimming in the rain
h) So he seen the pig
i) and he went over there
j) and picked the pig up
$\mathrm{k}$ ) and put it in the boat
1) and brought it back to the shore, so he would land there
$\mathrm{m})$ and that was that.

The original narrative was ten times longer, but even this shortened version seems odd. It contains a sequence of events that constitute the complicating action, but they "[...] are lacking the evaluation section that is typical of narratives of personal experience" (Labov \& Waletzky, 1967, p. 29). This results in uncertainty regarding how the piece should be interpreted, what the main point is and what the author is trying to achieve. The boundary between the complicating action and the result is also too fuzzy. The need to include evaluation in a story (narrative) springs from the observation that stories are "told in answer to some stimulus from the outside [...] to establish some point of personal interest" (Labov \& Waletzky, 1967, p. 29). Events are not presented for their own sake even if they are surprising, interesting and very reportable. This article has the goal of characterising evaluation as a unit of narrative/story and discuss ways in which it is performed. The examples used in the presentation come from L\&W2 (1967) and a study by Badio (2014). Section one attempts an extended definition of the category of evaluation as it is applied to narrative structure. Section three discusses evaluative signals often employed throughout a story, whereas section four provides numerous examples of strategies employed in a study in which the participants (advanced learners of English as a foreign language at the University of Łódź, Poland) were instructed to write a story on the basis of a certain baseline, input sequence of events. They wrote from the point of a wife, who had mistakenly placed a large amount of cash in the fireplace.

\section{Defining evaluation as an aspect of narrative}

Evaluation can refer to one event within a story, a set of events as well as to the whole narrative. When a single event is evaluated, a clause can be used, usually in irrealis mood or a set of clauses in the case of the whole section called evaluation.

\footnotetext{
${ }^{2} \mathrm{~L} \& \mathrm{~W}$ is used to stand for Labov and Waletzky.
} 
Evaluative commentary often spreads across the entire narrative and gets coded with the use of: emphasis, parallel structures, comparatives, modals, negatives, future forms, repetition and symbolic action. Evaluative clauses suspend the progression of events in the complicating action. Time, as if, slows down or even stops. This is perhaps less obvious in the case of single words and phrases added to clauses in the complicating action (Labov \& Waletzky, 1967, p. 33-34).

Evaluation was by these authors (Labov \& Waletzky, 1967, p. 35) demonstrated to exhibit variable 'embedding' or internality vs. externality (to a story). The following sentences from $\mathrm{L} \& \mathrm{~W}(1967$, p. 45) are provided to explain this point.

2) a) and when he got down there, her brother turned to me and whispered, "I think she's dead, John"

b) and when she got down there, I said to myself, "My God, she's dead!"

c) and when we got down there, I thought, "She's dead."

d) and when we got down there, I thought she was dead.

e) Later, the doctors told us she was close to death.

f) I think she must have been close to death.

g) You know, in cases like this, it's clear that she was likely as not dead.

The highest level of embedding of an evaluative comment within a narrative in which it is used is illustrated by example [2a]. The last comment in this clause, i.e., I think she is dead, John, quotes her brother and constitutes an event on a par with other events of the complication action sequence. Such a solution heightens the cognitive salience (cf. Talmy, 2007) of the information that she was probably dead by coding the source of this information, interlocutors and their relation. A reader or listener is invited to mentally simulate the whole situation together with the way the just quoted comment must have been whispered (as we are dealing with oral narratives). Naturally, if language is used to code specific aspects of an event or situation, they become foregrounded, more prominent and stand out in conceptualisation. Example [2b] by comparison codes the subjective event of thinking and the narrator quotes her/(him)self. [2d-f] become less specific in this respect. [2d] codes two events: that they got there and what the narrator thought; $[2 \mathrm{e}]$ is even more external to the main events of the story as a third party is introduced (doctors), not present in the sequence of the complicating action, whereas the whole of [2f] is the narrator's evaluative comment. [2g] is the most external and the least embedded evaluative comment within the sequence of events of the complicating action. The narrator distances her/himself from the actual story that has just been told in order to evaluate what happened.

Evaluation can be presented by the narrator "showing [her(him)self] in a favourable position [...] [with] the function of self-aggrandizement" L\&W 
(1967: p. 34). When the narrator (speaker in a conversation) wishes to put blame on another person for what had happened, s/he tends to use evaluative commentary. Apart from evaluating an event or a set of events, such a commentary may also serve the function of constructing causality within a narrative. In fact, these two functions (constructing causality and evaluating at the same time) are often merged.

\section{Evaluation signals in narrative}

The evaluation section can be performed by a number of linguistic devices: emphasis, parallel structures, comparatives, modals, negatives, repetition and use of symbolic action. The term emphasis applies to the use of a number of strategies whose purpose is heightened listener's or reader's attention on selected events, situations and their features. One way to achieve this result is by suspending the action and providing a narrator's comment on an event or a sequence of events just reported, as demonstrated in example [3] below.

3) I told him - it's impossible for him to find downstairs, cause all those people were walking by, and just his father is the only one that find it? (L\&W 1967, p. 34)

In this case the narrator criticizes the action of the other and performs selfpromotion. Emphasis can also be achieved by lexical intensifiers such as really, honestly, of course, and the use of very specific, often colloquial terms in the case of oral narratives, e.g., whooped instead of hit as in I whupped that dude half to death (L\&W, 1967, p. 32). Higher prominence resulting from the application of parallel structures is exemplified by such comments as: I knew he was bad, I knew he was a liar, I knew he would cheat on us. Comparative and superlative adjectives, e.g. better, far more advanced, the best are naturally evaluative and can be easily added to a story clause presenting an event that belongs to the complicating action sequence. Modal verbs, e.g. should, should have, could have express the story teller's stance towards presented events. There is a difference in He picked up the bits of broken glass from the floor as opposed to He should have picked up the bits of broken glass from the floor. The second sentence means he did not do it and also expresses the narrator's negative opinion (evaluation). Negative forms can be coded by both grammar and lexical items, and they can be added anywhere within a narrative to provide hints on how the narrator evaluates an event. For example, in Yeah .. he played truant, the adverb 'yeah' receives negative interpretation in the context of making a comment about a student who decided to miss classes on 
a particular day. Repetition certainly enhances the cognitive salience of an idea. For example, if one says, and he did it, he did it, the evaluation is communicated through the indirectly coded surprise at the fact that somebody took courage to perform an activity or an event. Last, the use of comments describing symbolic action, such as: you could hear the rosaries clicking, I crossed myself, up to his eyeballs in debt, is an example of evaluation that can be interspersed throughout the whole story and is culture dependent.

\section{Evaluation strategies in a EFL written stories}

The data for the present section comes from a study by Badio (2014) inquiring about strategies EFL story writers use to put blame on the other for something bad that has happened. The participants of this study were instructed not to change facts of the baseline story, but they were allowed to use other strategies of their own choice.

Divided into two groups, the EFL students had to retell in writing a story from the point of view of a wife to explain why a certain amount of money went up in smoke. One group had to be objective as far as possible, whereas the other one was told to blame the husband for the loss of money. The students employed: direct evaluative comments, subjective events, descriptions of routine behaviour, extensive elaborations of background information and character descriptions in order to negatively evaluate the role of the husband in this story.

\subsection{Use of events and circumstances to evaluate what happened}

In order to blame the husband for what happened, some participants decided to add information on events or circumstances that facilitated the wife's mistake of putting a brown paper bag full of money into a roaring fireplace. Some of them were actually provided in the baseline story, either in the orienting or complicating action sections. For example:

4) It was a late evening; it was about midnight

5) It was a very long day-work for my husband; He was tired

6) $[\ldots]$ that the client paid to my husband in cash

7) He wasn't able to do it [deposit the money] because all the banks were closed

8) Unluckily for us, he went to a restaurant [where he bought food and put the money in another brown paper bag from there]; and he kept 2000 pounds in a paper bag.

9) but he didn't reply 
All the above comments evaluate the most reportable (unfortunate) event of the story in slightly different ways. Numbers [4] and [7] describe conditions which facilitated the MRE. ${ }^{3}[4]$ is a comment that can also be understood as orienting in time. Its evaluating power lies in our understanding that late in the evening or night people tend to be tired and make mistakes. At the same time the comment builds the causality in the story. Because it was late, the husband was tired, so he did not hear when his wife asked about the brown paper bag left by him on the kitchen table. Examples [6] and [7] explain the need to carry cash around and an obstacle in depositing the money in the bank, which is evaluative because it justifies the need to bring the banknotes home. Comment [8] evaluates the circumstance of the husband visiting a fast-food bar after work at night, from where he took a brown paper bag to place money in. This is evaluated as unfortunate and out of control of the husband. Number [9] is a negative event, i.e. one that actually did not take place. The wife asked what was in the paper bag, but heard no reply. Though not directly stated, the evaluation of this event is that should the husband had answered the question, their money would not have been burnt to ashes. All the above comments code an event or circumstance and they are almost always both evaluative and causative, sometimes also orienting.

\subsection{Presentation of routine behaviour to evaluate what happened}

Routine is highly credible but seldom, if ever, reportable. That is why its use in the context of a story serves other purposes than the presentation of the development of the complicating action. Evaluation of what happened may be presented by displaying a character's routine behaviour. Let us consider the following examples from the study by Badio (2014).

10) because I saw this mess on the table, as usual

11) and, as usual, he left some trash on the kitchen table

12) my husband as usual was watching television

13) It is the thing we always do with flammable but not polluting stuff

The examples consist of two parts. One part codes an event performed by a character, whereas the other part informs that the event was typical, routine, or one that is negatively assessed by the other. Leaving the table untidy and watching TV all the time is not only considered disrespectful but also causal in the rather dramatic effect of wasting all the hard earned cash.

${ }^{3}$ MRE stands for the most reportable event in a story, here that a paper bag full of money was placed inside a fireplace and was destroyed. 


\subsection{Using subjective events (comments) to evaluate story events}

Another strategy that turned useful in blaming the husband for what happened was the frequent coding of the so-called subjective events, i.e. events whose truth value cannot be assessed.

14) I tried to ask him what he brought

15) and I answered that I thought there were rubbish so I threw it to the fire.

16) I had no idea what was inside the paper bag $\rightarrow$

17) but he seemed to be was so overwhelmed with the film

18) but I think my husband didn't do it

19) and didn't probably hear my question

20) I just wanted to throw out some rubbish

21) I swear I didn't know

22) I suppose he didn't hear my question

23) I was sure that it was not anything important

24) It is the thing we always do with flammable but not polluting stuff

They all express the idea that the wife made the terrible mistake of burning the money because she: thought, believed, wondered, which frees her from feeling guilty, at least to some extent. At the same time, and as in the case of the other strategies described above in this section, also the use of subjective comments serves the purpose of evaluating what happened and constructing causality.

\subsection{Presentation of one's character to evaluate what happened}

Comments regarding a person's character features, positive or negative, can also be used to evaluate events belonging to the complicating action of a story. In the case of the study described in this section, the students writing from the point of view of the wife, invented all kinds of negative commentary describing the husband's character. As in the case of other sub-sections of section four, they were used not only to evaluate but also to construe causality. The following comments illustrate this point:

25) My terrible husband

26) and, to be true with myself, he was never the one too tidy or organized in the house

27) I know that my husband works very late, and it irritates me

28) He never has time for me - to speak freely or go on a holiday simply

29) My husband is not supposed to do anything at home; he is a terrible slob

30) Who puts money in paper bag and leaves it on the kitchen

31) My husband never listens to me 
The first comment in example [25] uses a general adjective with negative connotations; [26] refers to the husband's untidiness, short-sightedness [27] and inability to strike a work-life balance, ignorance of his wife [28] and laziness [29], even stupidity and inability to predict consequences of his actions [30] and finally inability to listen, living in his own world [31]. The features negatively assess the husband's role in the MRE, but are also portrayed to explain the causal relations within the story, i.e. how it was possible that the MRE happened.

\subsection{Extensive elaboration of the background (quasi orientation) as a way to evaluate what happened}

This is still another category in the pool of evaluation strategies put to action by the participants of the described study by Badio (2014). Some participants wrote (from the point of view of the wife) lengthy descriptions of their marriage situation and life in general. For lack of space only two of them are quoted below.

32) Everything as usual. I know that my husband works very late, and it irritates me. He never has time for me - to speak freely or go on a holiday simply. But I must live with him. He's my husband. I was so tired.

33) My husband is never listening to me. Never. But finally he received his punishment. But let me tell the story from the beginning. During our courtship it was all perfect. We used to talk much, sometimes about serious things but also about some silly events from our lives. I remember how he used to complain about how silent and introverted I am and insisted I should talk more and more. After marriage, they say, people change. And so did my husband and I. Now he prefers to listen to the radio, to the television, or his stupid friends' stories than to things I have to say that are so crucial to me. He ignores me, disrespects me. I cried at nights and could not make up any solution to his absence of mind. But now I know karma exists.

In example [32] the wife in one story said nothing strange was going on. Evoking the usual and comparing it to the dramatic events of one evening, during which a large sum of money went up in smoke, constitutes an evaluation and a construal of the idea the wife is not to be blamed for the incident. The comment is then followed by stereotypical ideas of (Polish) marriage problems: the husband is blamed for never having enough time to spend with the wife, going on holiday together and feeling tired. The next example [33] is similar in this respect to [32], but is longer. The selected cultural stereotype in this case is the one in which the time of courtship before marriage tends to be a happy and care-free period, but after marriage at least one of the spouses (here the husband) changes for the worse and ignores the other half. This story contains details of events, such as he prefers 
listening to the radio, and only the final comment is a more direct evaluative statement, but I know karma exists. The wife says that the incident of incinerating the large sum of money in the fireplace happened because their marriage has changed for the worse. Such a description both evaluates the MRE and construes the cause-effect links (the participants were instructed to write from the point of view of the wife in order to blame the husband for wasting 2000 pounds).

\subsection{Direct evaluative comments}

This category involves narrator's comments that are directly evaluative. All examples in this section evaluate the unfortunate event of burning 2000 pounds in the fireplace by mistake. The reader is reminded that this study asked the participants to write from the wife's point of view (one condition) and be as objective as possible or blame the husband (the other condition). Such an instruction excluded feeling a great deal of empathy for the other, especially in the 'blame husband' condition. A selection of direct evaluative comments are presented below.

34) I assumed it was to be put in the fireplace.

35) Unluckily for us, he went to a restaurant.

36) Of course I had no idea that he would keep such a great amount of money in a paper bag.

37) $[\ldots]$ he should have known that keeping money in a paper bag that looked as rubbish is not a good idea.

38) It is not my fault that he hadn't told me that all banks were closed and he kept 2000 pounds in a paper bag.

39) I decided to clean the kitchen and living room. I know it was late, but I was too tired to do this earlier.

40) It was a very long day-work for my husband.

41) I suppose he didn't hear my question.

42) Frankly speaking, when I saw my husband fighting with a fire I was ready to call an ambulance.

43) [...] and wasn't surprised at all (at what happened, i.e. that the money went up in soke).

Example [34] offers an explanation that the wife assumed the brown paper bag needed to be disposed of on the grounds that the husband had left it lying among other left-overs and rubbish on the kitchen table. Her assumption is presented as an evaluation of what she did. Comments [35] and [36, 37, 38] contain direct evaluative adverbs, unluckily and of course. The former refers to the event of the complicating action, whereas the latter three examples pertain to the idea that the wife was not able to predict that the husband would be so irresponsible as to keep 
a large sum of cash in a brown paper bag. Further, the mistake of placing the hard earned cash into the fire is attributed in examples $[39,40]$ to feeling tired late in the evening, also the husband's inattentiveness in the evening (example [41]). Comment [42] evaluates the wife's emotions at the time the husband was trying to rescue the money from the flames, and [43] refers to how she felt after the money was burnt given her non-acceptance of the husband's general attitude and relations between the spouses.

\section{Conclusions}

In sum, presenting a sequence of complicating action events without some evaluation of their meaning, importance or a character's affective response to them does not constitute a story. Events in a narrative need to be evaluated in order for the narrator to be able to make a point beyond the literal interpretation of the narrative events. Story tellers evaluate single events, their sets or the whole narrative. Evaluation can be performed by single words or phrases added to events that belong to the complicating action section, or it is coded in separate evaluative clauses. L\&W's (1967) and Labov's (1997) ground-breaking work on oral narratives has been reported regarding evaluation. Evaluation was shown to be coded into the form of emphasis, parallel structures, comparatives, modals, negatives, repetition and symbolic action. Moreover, a study by Badio (2014) has been used to provide example strategies employed by non-native, advanced learners of English as a foreign language in a story construal task. They tended to employ at least one of the following strategies to evaluate what happened: use of an event from the complicating action, description of routine behaviour, use of subjective events, description of a person's negative personality features, extensive elaboration of background information, quasi-orienting comments as well as direct evaluative clauses. What is important to emphasize is that the above mentioned strategies not only serve the purpose of evaluating events but they also perform an important role in the construal of blame and causal structure of a story.

\section{References}

Badio, J. (2014). Construal and Linguistic Coding of Narrative Events. Łódź: Wydawnictwo Uniwersytetu Łódzkiego.

Badio, J. (2020). Narrative as a radial category. Studia Anglica Posnaniensia: An International Review of English Studies. In press. 
Ervin-Tripp, S. M. \& Küntay, A. (1997). Conversational stories. In T. Givón (ed.), Conversation: Cognitive, Communicative and Social Perspective, (pp. 133-136). Amsterdam: John Benjamins.

Filar, D. (2016). Narrativity as a semantic category. In J. Badio (ed.), Events and Narratives in Language, (pp. 117-129). Frankfurt am Main: Peter Lang.

Kiełkiewicz-Janowiak, A. (2016). A narrative-discursive approach to life stories: towards transdisciplinarity. In J. Badio (ed.), Events and Narratives in Language, (pp. 157-169). Frankfurt am Main: Peter Lang.

Labov, W. \& Waletzky, J. (1967). Narrative analysis. In J. Helm (ed.), Essays on the Verbal and Visual Arts. Seattle: University of Washington Press, (pp. 12-44). Reprinted in the Journal of Narrative and Life History 7, 3-38.

Labov, W. (1997). Some further steps in narrative analysis. Journal of Narrative and Life History 7 , $395-415$.

Talmy, L. (2007). Attention Phenomena. In D. Geeraerts \& H. Cuyckens (eds.), The Oxford Handbook of Cognitive Linguistics, (pp. 264-294). Oxford: Oxford University Press. 